\title{
Open educational resources: staff attitudes and awareness
}

\author{
Vivien Rolfe* \\ Faculty of Health and Life Sciences, De Montfort University, Leicester, UK \\ (Received 25 October 2010; final version received 27 April 2011)
}

\begin{abstract}
Attitudes are changing in education globally to promote the open sharing of educational courses and resources. The aim of this study was to explore staff awareness and attitudes towards "open educational resources" (OER) as a benchmark for monitoring future progress. Faculty staff $(n=6)$ were invited to participate in semi-structured interviews that facilitated the development of a questionnaire. Staff respondents $(n=50)$ were not familiar with the term OER but had a clear notion of what it meant. They were familiar with open content repositories within the university but not externally. A culture of borrowing and sharing of resources exists between close colleagues, but not further a field, and whilst staff would obtain resources from the Internet, they were reticent to place materials there. Drivers for mobilising resources included a strong belief in open education, the ability of OER to enhance individual and institutional reputations and economic factors. Barriers to OER included confusion over copyright and lack of IT support. To conclude, there is a positive collegiate culture within the faculty, and overcoming the lack of awareness and dismantling the barriers to sharing will help advance the open educational practices, benefitting both faculty staff and the global community.
\end{abstract}

Keywords: open educational resources; staff attitudes; sustainability

\section{Introduction}

The Massachusetts Institute of Technology (MIT) first talked about placing learning materials for free on the Internet in 2001 (Goldberg 2001), and soon after the term "Open Educational Resources" (OER) emerged and was defined as: "educational resources, enabled by information and communication technologies, for consultation, use and adaptation by a community of users for non-commercial purposes" (UNESCO 2002). As the OER movement has gained momentum, so has the definition expanded to embrace the benefits of providing opportunities for knowledge transfer and to facilitate the sharing of best practices (The William and Flora Hewlett Foundation 2010).

Central to the growth of the use of OERs has been the technological developments supporting the production and retrieval of resources, and the emergence of a clear and simple licensing mechanism under Creative Commons (Bissell 2009). Since the first MIT initiative, the number of repositories storing OER has grown in number and constantly shifts (CERI and OECD 2007; Friesen 2009). The OER placed in these repositories range in granularity from whole courses such

\footnotetext{
*Email: vrolfe@dmu.ac.uk

RLT 2012. (C) 2012 V. Rolfe. Research in Learning Technology is the journal of the Association for Learning Technology (ALT), a UK-based professional and scholarly society and membership organisation. ALT is registered charity number 1063519. http:// www.alt.ac.uk/. This is an Open Access article distributed under the terms of the Creative Commons "Attribution 3.0 Unported (CC BY 3.0)" license (http://creativecommons.org/licenses/by/3.0/) permitting use, reuse, distribution and transmission, and reproduction in any medium, provided the original work is properly cited. 
as those offered by the OpenCourseWare Consortium (OCWC 2011), to materials and learning objects such as those available on the Multimedia Educational Resource for Learning and Online Teaching (MERLOT 2011) and to raw asset files (Jorum 2011). Search for free open educational resources on Jorum and this retrieves $>12,000$ items licensed for use worldwide under Creative Commons, giving users permission to reuse resources with a minimal restriction such as a requirement to attribute the author, to share alike or to prevent commercial use (Creative Commons Organisation 2011).

One of the major challenges that the OER movement faces if it is to flourish is that of long-term sustainability (Atkins, Brown, and Hammond 2007; D'Antoni 2008). As Friesen notes (2009), the lifespan of a content repository can be fragile, and in his example he describes 11 repositories that were discontinued in the present decade, of which only two were over 5 years old. There are many factors that contribute to sustainability, central to which is the role that institutional staff play in producing and using the content, and many staff have already voluntarily chosen to champion and pioneer OER. Downes (2007) describes the importance of staff, partnerships and communities in the OER movement, and also academic staff are fundamental to providing quality assurance and learner support that are important drivers of sustainability (D'Antoni 2008).

If institutional staff are to play such a critical role as indeed they have up to now, it is essential to understand their attitudes and behaviours towards OER to provide a benchmark to monitor progress and to identify strategies for training and support. A small number of studies have explored staff attitudes towards OER. In a global questionnaire of 193 institutional managers from 49 countries, the most significant barriers surrounding the use of OER included the lack of time and lack of a reward system (CERI and OECD 2007). The strongest perceived opportunity was the ability to gain access to the best quality materials. Fundamental to the sustainability of OER is the notion of sharing, and a smaller survey of 109 faculty members investigated more deeply about staff perceptions of knowledge sharing in a Korean institution and drivers for this activity were identified as having a clear purpose and necessity to share, along with relevant reward systems (Kim and Ju 2008). One further study evaluated the incentives and disincentives from the view of the general public in relation to the OpenCourseWare initiative, where incentives to using OER included the fact there was no associated cost and that resources were available at any time to enable the user to pursue a subject of interest (Arendt and Shelton 2009).

The aim of the current research was to explore staff awareness and behaviours surrounding OER with a focus on attitudes to sharing resources, to provide benchmarks for monitoring future progress of these new educational practices as they develop. In this study, the term 'open educational resource' was assumed to refer to high-quality, open-licensed materials available for global use (The William and Flora Hewlett Foundation 2010). An abstract of this paper was presented at OER 2010 (Rolfe 2010a).

\section{Material and methods}

\section{Questionnaires and interviews}

In 2009, academic staff from the Faculty of Health and Life Sciences were invited to participate in preliminary interviews $(n=6)$ that were semi-structured, recorded and 
transcribed. The content was analysed by clustering the statements obtained into emerging themes, facilitated by the use of a spreadsheet (Rolfe et al. 2008). The interview responses were used to form the basis of a questionnaire that contained questions on: (1) basic demographics, (2) awareness of the term OER and where to find OER and (3) an analysis of staff attitudes and experiences of open content and associated behaviours. Staff attitudes were evaluated using a 5-point Likert Scale where 1 indicated "strongly disagree" and 5 represented "strongly agree". Some questions were open ended. The questionnaires were distributed online via the tool Survey Monkey and by paper copy and were made available for 1 month. All staff were e-mailed regarding the survey and one reminder was issued. A prize incentive was offered.

\section{Statistical analysis}

Data were analysed using a Chi-squared test and Mann-Whitney $U$ Test. Significance was assumed at $p<0.05$. Attitudinal data are presented as the mean Likert response \pm standard deviation (SD).

\section{Results}

\section{Staff demographics}

Out of 307 academic staff (full time and part time), there were 50 survey responses (16\% of staff), in which $66 \%$ of respondents were female and $34 \%$ were male. Participation was evenly split across the four academic schools (Table 1).

\section{Awareness of OER and technologies}

In total, nine staff members $(18 \%)$ had heard of the term OER (Table 2). Around half were aware of the university video library and half were aware of DORA, an open research paper archive, of which the proportion of male colleagues aware was

Table 1. Staff demographics.

\begin{tabular}{lccc}
\hline & Female & Male & Total \\
\hline $\begin{array}{l}\text { No. of respondents age } \\
\text { (years) }\end{array}$ & 33 & 17 & 50 \\
$30-39$ & 7 & 2 & 9 \\
$40-49$ & 12 & 8 & 20 \\
$50-59$ & 13 & 6 & 19 \\
$60+$ & 1 & 1 & 2 \\
Time in faculty (years) & & 5 & 18 \\
$0-5$ & 13 & 3 & 14 \\
$6-10$ & 11 & 5 & 12 \\
$11-20$ & 7 & 4 & 6 \\
$>21$ & 2 & 6 & 13 \\
School & & 4 & 14 \\
Pharmacy & 7 & 3 & 11 \\
Nursing and midwifery & 10 & 4 & 12 \\
Allied health sciences & 8 & & \\
Applied social sciences & 8 & & \\
\hline
\end{tabular}


Table 2. Awareness of OER and associated technologies.

\begin{tabular}{lcccc}
\hline $\begin{array}{l}\text { Tick the box(s) to indicate which of the } \\
\text { following you have heard of? }\end{array}$ & $\begin{array}{c}\text { Female } \\
(n=33)\end{array}$ & $\begin{array}{c}\text { Male } \\
(n=17)\end{array}$ & $\begin{array}{c}\text { Total } \\
(n=50)\end{array}$ & Total\% \\
\hline Open educational resources (OER) & 4 & 5 & 9 & 18 \\
DMU Video Library & 18 & 8 & 26 & 52 \\
DMU DORA & 13 & $13^{*}$ & 26 & 52 \\
YouTube EDU & 14 & 11 & 25 & 50 \\
iTunesU & 13 & 8 & 21 & 42 \\
Virtual Analytical Laboratory (VAL) & 11 & 7 & 18 & 36 \\
MIT & 11 & 2 & 13 & 26 \\
ALT Open Access Repository & 5 & 6 & 11 & 22 \\
Jorum & 5 & 5 & 10 & 20 \\
Bioscience Image Bank & 4 & 4 & 8 & 16 \\
Bristol BioMed Image Archive & 3 & 2 & 5 & 10 \\
\hline
\end{tabular}

${ }^{*} p<0.05$, Chi-square test (female vs. male)

significantly higher than female staff $(76 \%$ vs. $39 \%$, respectively, $p<0.05)$. The Virtual Analytical Laboratory (an open laboratory skills resource) was familiar to $36 \%$ of staff. Only $20 \%$ had heard of Jorum, and fewer had heard of biosciencerelated repositories that reflected the subject profile of the staff population that also includes healthcare professions. Despite the claimed lack of awareness of OER, the meaning of the term appeared reasonably self-explanatory and clear to staff, eliciting the following open responses:

Freedom to share learning and teaching resources created by any member of the University to improve the student experience.

Open access to resources and materials for learning.

\section{Attitudes and behaviours surrounding borrowing and sharing resources openly}

The next section of the questionnaire explores current working practices in relation to sharing and borrowing resources. The results indicated that three quarters of staff currently share and borrow learning resources, mostly with close working colleagues (Table 3). Higher numbers of female staff members shared and borrowed compared to male colleagues $(p<0.05)$. Also, $50 \%$ of staff obtained resources from the Internet, whilst only $12 \%$ placed resources there to make them globally available.

Staff attitudes to borrowing and sharing were then explored more deeply using a series of statements and a Likert Scale, where 1 represented strongly disagree and 5 represented strongly agree. Overall, male and female staff shared similar attitudes to sharing and borrowing resources $(p>0.05$, Mann-Whitney $U$ Test, data not shown), so that the total data were pooled and are presented in Table 4 . When asked to indicate how they felt about sharing, strong drivers for sharing resources included a belief in open education and as a reputation enhancer both for the institution and the individual. Strong drivers for borrowing were for economic reasons. Staff shared a collegiate attitude, and statements regarding the idea that sharing gives colleagues an advantage, or that staff wanted to work individually, were weakly expressed. 
Table 3. Borrowing and sharing behaviour.

\begin{tabular}{|c|c|c|c|c|}
\hline Statement & $\begin{array}{l}\text { Female } \\
(n=33)\end{array}$ & Male $(n=17)$ & Total $(n=50)$ & Total $\%$ \\
\hline \multicolumn{5}{|l|}{$\begin{array}{l}\text { Do you make your materials } \\
\text { available to others to share? }\end{array}$} \\
\hline Yes & 25 & 12 & 37 & 74 \\
\hline No & 3 & 4 & 7 & 14 \\
\hline Unanswered & 5 & 1 & 6 & 12 \\
\hline \multicolumn{5}{|l|}{$\begin{array}{l}\text { To whom do you make your } \\
\text { resources available? }\end{array}$} \\
\hline $\begin{array}{l}\text { Academic colleagues who you } \\
\text { work closely with }\end{array}$ & $24^{*}$ & 9 & 33 & 66 \\
\hline $\begin{array}{l}\text { Academic colleagues within the } \\
\text { faculty }\end{array}$ & 10 & 8 & 18 & 36 \\
\hline $\begin{array}{l}\text { Other academic colleagues, for } \\
\text { example, through a subject } \\
\text { network }\end{array}$ & 9 & 4 & 13 & 26 \\
\hline $\begin{array}{l}\text { Academic colleagues outside } \\
\text { the faculty but in DMU }\end{array}$ & 5 & 6 & 11 & 22 \\
\hline $\begin{array}{l}\text { Openly available to anyone } \\
\text { who wants them globally }\end{array}$ & 4 & 2 & 6 & 12 \\
\hline Unanswered & 3 & 3 & 6 & 12 \\
\hline \multicolumn{5}{|l|}{$\begin{array}{l}\text { Do you use resources that have } \\
\text { originated elsewhere? }\end{array}$} \\
\hline Yes & 25 & 13 & 38 & 76 \\
\hline No & 3 & 3 & 6 & 12 \\
\hline Unanswered & 5 & 1 & 6 & 12 \\
\hline \multicolumn{5}{|l|}{ Where do you obtain resources? } \\
\hline $\begin{array}{l}\text { Academic colleagues who you } \\
\text { work closely with }\end{array}$ & $21^{*}$ & 6 & 27 & 54 \\
\hline $\begin{array}{l}\text { Resources taken from the } \\
\text { Internet }\end{array}$ & 16 & 9 & 25 & 50 \\
\hline $\begin{array}{l}\text { Resources supplied through a } \\
\text { textbook manufacturer }\end{array}$ & 13 & 9 & 22 & 44 \\
\hline $\begin{array}{l}\text { Other academic colleagues, for } \\
\text { example, through a subject } \\
\text { network }\end{array}$ & 6 & 8 & 14 & 28 \\
\hline $\begin{array}{l}\text { Academic colleagues within the } \\
\text { faculty }\end{array}$ & 6 & 7 & 13 & 26 \\
\hline $\begin{array}{l}\text { Academic colleagues outside } \\
\text { the faculty but in DMU }\end{array}$ & 2 & 4 & 6 & 12 \\
\hline
\end{tabular}

${ }^{*} p<0.05$, Chi-square test (female vs. male).

\section{Activity and attitudes in new staff versus longer standing staff members}

The data were divided into staff who had worked in the faculty 10 years or less $(n=32)$ and longer standing members of staff who had been employed by the faculty for 11 years or more $(n=18)$. Data from Tables 3 and 4 were reanalysed. There was no significant difference in the levels of activity between the two groups $(p>0.05$, Chi-squared test and Mann-Whitney $U$ Tests), with the exception that the proportion of newer staff members borrowing from colleagues was higher than longer standing members ( $96 \%$ vs. $68 \%$, respectively, $p<0.05$ ), and new staff were 


\section{Rolfe}

Table 4. Staff attitudes towards using educational resources.

\begin{tabular}{lll}
\hline Statement & Mean & SD \\
\hline Indicate how do you feel about SHARING your & \\
educational resources? & & \\
I believe in open education & 4.1 & 0.6 \\
OER enhances the reputation of my institution & 4.0 & 0.7 \\
Sharing resources enhances my reputation as a good teacher & 3.9 & 0.8 \\
I'd be happy for someone to adapt my resources & 3.9 & 0.8 \\
I would need to be acknowledged as the author & 3.7 & 0.7 \\
I have no support for making materials openly available & 3.3 & 1.1 \\
I have concerns over copyright & 3.2 & 1.1 \\
Why give away resources to other universities & 2.3 & 0.9 \\
I don't wish to give colleagues the advantage of using my & 2.2 & 1.2 \\
resources & & \\
I don't wish to share resources that I've spent a long time & 1.9 & 0.8 \\
preparing & & \\
How do you feel about BORROWING educational resources? & & \\
Borrowing resources saves time and money & 4.0 & 0.6 \\
I only use resources from someone I know and trust & 3.5 \\
I have trouble finding resources of high enough quality & 3.3 & 1.0 \\
I'd only use resources recommended by someone I know & 3.2 & 1.0 \\
and trust & & 0.9 \\
It is not easy to adapt resources to meet my needs & 3.1 & 1.0 \\
I don't really know where to look for them & 2.8 & 1.1 \\
I prefer to work individually and use my own resources & 2.7 & 0.9 \\
\hline
\end{tabular}

Likert scale data where $1=$ strongly disagree and $5=$ strongly agree.

more likely to borrow from close colleagues than more experienced staff $(75 \%$ of newer staff vs. $37 \%$ of longer standing staff, $p<0.05$ ).

Newer staff members had greater concerns over copyright and were more positive towards the notion that "borrowing resources saves time and money", whereas longer standing members of staff viewed more positively the statements "it is not easy to adapt resources to meet my needs" and "I prefer to work individually and use my own resources" ( $p<0.05$, Mann-Whitney $U$ Test).

\section{Activity and attitudes by age group}

The data were divided into age groups, 30-49 years $(n=29)$ versus 50 plus $(n=21)$. Data from Tables 3 and 4 were reanalysed. There was no significant difference in the attitudes and behaviours between the two groups $(p>0.05$, Chi-square test and Mann-Whitney $U$ Tests).

\section{General comments regarding OER implementation}

The following preferences were offered as incentives to engaging in OER in the future (Table 5), and the results show that the strongest preferences included the need for technical and IT assistance, and clarity over copyright, whereas a lower priority was the need for incentives for people to produce resources. When asked about copyright ownership in more detail, just over half $(54 \%)$ of the total staff thought that copyright for educational resources resided with the university, but $24 \%$ were unclear, 
Table 5. General comments regarding OER implementation.

\begin{tabular}{lcrcc}
\hline Statement & Female & Male & Total & Total $\%$ \\
\hline $\begin{array}{l}\text { What infrastructure, help and rewards would you } \\
\text { like to see? }\end{array}$ & 24 & 8 & 32 & 64 \\
$\begin{array}{l}\text { IT/technical assistance } \\
\text { Clarity over copyright }\end{array}$ & 22 & 10 & 32 & 64 \\
Staff development & 22 & 7 & 29 & 58 \\
Incentives for people who develop the resources & 17 & 7 & 24 & 48 \\
$\begin{array}{l}\text { The use of open source services, for example, } \\
\text { YouTube, Picassa, (open to all) }\end{array}$ & 13 & 8 & 21 & 42 \\
$\begin{array}{l}\text { An institutional repository (resources open to } \\
\text { DMU staff \& students) }\end{array}$ & 14 & 5 & 19 & 38 \\
$\begin{array}{l}\text { Blackboard (resources open to DMU staff \& } \\
\text { students) }\end{array}$ & 11 & 7 & 18 & 36 \\
Wider use of external repository, for example, & 9 & 6 & 15 & 30 \\
JORUM (open to all) & & & &
\end{tabular}

and $16 \%$ felt that resources were copyright of the individual. In fact, the situation is complex with electronic resources copyright of the university, although other forms of teaching material are copyright of the individual member of staff.

In a final section on the questionnaire, staff opinion of OER was expressed in an open comment section. Staff comments raised the notion of needing a clear institutional strategy and a clear vision of the purpose for becoming involved in OER and how an institution could ensure that contributions were duly recognised:

A clear purposeful reason why it is good for me personally and for the institution.

A strong coherent strategy, not a half hearted, two or three people do all the work with no proper policy.

Danger that other people nick your ideas and get all the credit in an institute which may be seen to be lacking in OER.

\section{Interview responses}

The initial interviews that led to the development of the questionnaire themes highlighted levels of awareness and understanding of OER by staff, which were similar to the survey results, with staff perhaps not having heard of the term but having a relatively clear understanding of what it meant. As reflected by the survey, the perception of sharing and borrowing activity going on within the institution was strong, and there were benefits to be gained:

I would have thought it was something we should be doing more of because I would have thought there are a lot of people that continually re-invent the wheel.

What I want to encourage is between us we can share material in a way that we can releases ourselves for sabbaticals.

I would be quite happy with that, the ultimate aim is to get it as widely shared out as possible. If you develop a wonderful resource and only 3 people ever see it well it's not much of a resource is it.

The interviews identified barriers to sharing resources, which included time and IT infrastructure and other barriers that were deeper rooted and more personal and that 


\section{Rolfe}

did not materialise through the questionnaire. Whilst the idea that staff shared resources was clearly articulated in the initial interviews and the questionnaire, it is perceived that some staff do not participate, and perhaps this was linked to staff feeling insecure and, therefore, protecting their own work. The need for recognition was also expressed once more, and it was interesting to gain a perspective from staff who are asked to borrow resources and are then rebutted or those staff who produce materials yet do not have the opportunity to share them. These comments suggest how the activities of sharing and borrowing, central to the growth and sustainability of open educational practices, are entrenched in both professional and personal feelings and attitudes.

\section{Ownership and security}

I think some people see it as their resources, they have spent their time doing it and they think therefore they are theirs.

I think there is a feeling of well if it is available anyone can do it, you would be indispensable if you know what I mean. I think it's to do with job security and things like that.

\section{Confidence}

Some people won't do it so you can ask and you will get knocked back and that kind of puts you off.

And also I suppose nobody asks really so you don't really assume that anybody else would want your resources.

\section{Recognition}

You wouldn't want somebody who is not prepared any lecture notes to nick yours that you have spent all weekend doing. The scales have got to be equal rather than tipped in one persons favour.

\section{Discussion}

The use of OER and understanding of open educational practices is advancing globally, and in the United Kingdom, large numbers of individuals and institutions are contributing in particular through the Higher Education Funding Council for England (HEFCE) OER Programme presently run by the Higher Education Academy (HEA) and the Joint Information Systems Committee (JISC), (JISC 2010). How to grow and sustain these open educational practices is a major challenge, and operational models have described financial, technical and contentbased solutions, but more current thinking is placing staff and communities at the heart of the sustainability of OER (D'Antoni 2008; Downes 2007). Despite this, only one published study has looked at institutional staff awareness and attitudes to OER (CERI and OECD 2007), although there is a wealth of research ongoing as part of the OER Programme, and much to be learned about sharing, use and reuse from previous work on reusable learning objects. The current study, therefore, contributes to the understanding of staff awareness, attitudes and behaviours surrounding OER 
in a UK University and identifies both incentives and barriers to mobilising resources. The survey is openly available to use and repurpose (Rolfe 2010b).

In the current study, 50 staff members responded to the survey representing $16 \%$ of total academic staff, which although was a small sample, did equally represent all four schools. This is a reasonable response rate for a voluntary questionnaire, and these figures, perhaps, reflect the lack of awareness of OER at this moment in time of the study (staff interviewed and sampled in 2009). The present aim was to provide a snapshot of staff opinion and activity in time and to provide benchmarks for monitoring future progress and activity as OERs are promoted and institutional strategy evolves.

\begin{abstract}
Awareness
In total, nine staff members $(18 \%)$ had heard of the term 'open educational resources'. No comparable published survey data exists, although the results of a recent survey of global health care professionals and scientists with an interest in Sickle Cell and Thalassemia revealed that out of 226 respondents, $42 \%$ were aware of the term 'open educational resources' (Rolfe, Fowler, and Dyson, forthcoming), potentially a higher figure due to increased awareness in the United States where many of the respondents were located. In the present survey, half of the respondents were aware of the institutional repositories for video and research publications, although only one fifth had heard of Jorum, an external free online repository service developed for United Kingdom Further and Higher Education that promotes the sharing of OER globally. Staff had a clear understanding of what the term OER meant, which was an important outcome because the clarity of terminology is essential for the positive engagement of people in new ideas and initiatives. In a previous survey of staff attitudes towards e-learning, academic staff were unclear as to what e-learning meant or the types of technologies involved, were less aware of the potential benefits and less likely to adopt e-learning strategies in their teaching (Rolfe et al. 2008). Our current study, therefore, endorses the term OER as one that, although the majority of staff had not heard of, the name does clearly relay the activities that it represents.
\end{abstract}

\title{
Activity and attitudes
}

Fundamental to the OER movement is an individual's desire to borrow and share resources, and for institutions to cultivate collegiality. Our results show a strong tendency of faculty staff to freely share resources with immediate colleagues, with female colleagues significantly more active than male staff. This concords with previous findings of a multi-centre study with 130 respondents, which looked at attitudes towards sharing e-learning resources (Bell and Rothery 2006). Sharing occurred locally, but staff were apprehensive about making resources more openly available. In our survey, when considering OER more broadly, although half of the staff obtained resources from the Internet, only $12 \%$ claimed to place resources there to make them globally available, and again a similar picture in Bell and Rothery's study with only $6 \%$ of respondents making their educational materials openly available. As Dholakia, King, and Baraniuk (2006) suggested in their literature review in which they propose a model for OER sustainability, central to sustainability is the community and growth of a critical mass of interested individuals and it adopting technologies and approaches to create networks and discussion. Then, a 
vibrant community emerges. In our faculty, there is clearly a positive element on which to build on, but understanding the motivations and characteristics of potential users is important to develop strong and sustainable strategies and practices.

It is vital to understand the drivers and motivational forces behind adopting OER and to identify barriers and challenges. In the current study, the strongest drivers for sharing and borrowing included a belief in open education, as a reputation enhancer both for the institution and the individual, and economic factors that were a significant reason for participating. Staff shared a collegiate attitude, and statements that OER would give colleagues advantages and wanting to work individually were weakly expressed, although deeper rooted concerns were more readily expressed during the interviews. In the interviews, staff were concerned with job security and wanted clear recognition for time spent producing OER. Some staff lacked the confidence to make their resources available. In a multi-national survey of institutional managers (CERI and OECD 2007), they perceived that staff barriers to the use of OER would include time and skills, and barriers to producing OERs would be lack of reward systems, but this surveys none of the more personal attitudes such as lack of confidence or lack of job security.

These motivational factors are different to those observed in other studies, reflecting the idiosyncratic nature of institutions and departments, and differences in research techniques. Larsen and Vincent-Lancrin (2005) suggested a strong motivational force for people to make OER available was that material would be adopted and modified by others. Kim and Ju (2008) observed in a Korean University that staff strongly viewed knowledge sharing as an important motivator, and similar to our study, a lack of trust, openness and IT infrastructure were not expressed by staff as strong dissuading factors. This study selected staff randomly and therefore might have produced a fairer picture of opinions than the current study that was self-selecting.

\section{OER moving forwards}

In terms of OER moving forwards within the institution, staff expressed a need for IT and technical assistance, clarity over copyright and staff development. Copyright is a recurring barrier, and when questioned, staff were mixed as to their understanding of where the copyright of educational materials resided, with the university, the faculty or the individual? Similar confusion in the ownership of digital materials was observed in Bell and Rothery's study (2006). Institutions need to provide clear and transparent copyright policies and guidance, and articles such as that by Bissell (2009) that explain about open licences should be used as a starting point since it provides clear recommendations to educators and policy makers on how to proceed with copyright licensing for OER. Other information sources, including JISC Legal, explain the permissions that need to be obtained to mobilise material, and where these permissions might lie (JISC Legal 2011).

The role of individual pioneering staff is fundamental to the long-term sustainability of the OER movement, but institutions need to provide support and resources to embed OER into educational practices (Atkins, Brown, and Hammond 2007). As with e-learning in general, a sustainable approach requires cultural and institutional change, where staff share visions and are supported by organisational structures (Gunn 2010). In theory, the emergence of strong communities will provide a self-fulfilling prophecy, providing a community of producers, users and re-users (Dholakia, King, and Baraniuk 2006) and also providing a motivational force to 
sharing work (Larsen and Vincent-Lancrin 2005). Many OER projects, such as the "HumBox" repository, have achieved an end-user community and through this have demonstrated that user activity extends beyond initial project activity (Borthwick and Dicken 2010), and this addresses the view of Downes (2007) describing the importance of all staff and partnerships in the building of OER communities.

\section{Study limitations}

Different institutions will have different cultural contexts. The current study was limited to one faculty within one higher education institution. The survey sample was small with 50 respondents, and larger scale studies are required in multiple centres to provide a rich body of data from which to draw conclusions. The interviews yielded a broader selection of views than the open questions could ascertain, so further research needs to incorporate appropriate methodologies for obtaining a richness of opinion. Selecting participants on a voluntary basis is likely to engage more proactive staff, so responses may well be more positively biased. An alternative strategy would be the randomised selection of participants and employing alternative market research strategies for improving the response rate.

\section{Conclusion}

As interest in OER advances in the United Kingdom, it will be critical to understand staff attitudes and behaviours surrounding it, particularly in a climate of growing financial constraint. The current study provided an evaluation of staff perceptions of OER and associated behaviours and found that, although staff were unfamiliar with the term 'open educational resources', it was rather self-explanatory, and this should ease the promotion of further training and activities. There is already a culture of localised sharing and borrowing of material, but for staff to engage in open education practices beyond the institution, work needs to be done to explore the wider barriers. These might include some of the more deep-rooted concerns that emerged in the interviews, and these would need to be explored to successfully transform working practices. This study provides a benchmark against which to monitor future progress and also identifies pitfalls that need to be addressed to build a sustainable programme of OER production, use and reuse within the institution.

\section{Acknowledgements}

The author thanks the UK Subject Centre for Bioscience for supporting this project as part of their Open Educational Resource Phase 1 Project "An interactive laboratory and fieldwork manual for the biosciences".

\section{References}

Arendt, A. M. \& Shelton, B. (2009) 'Incentives and disincentives for the use of Open Course Ware', International Review of Research in Open and Distance Learning, vol 10, no. 5, pp. 126.

Atkins, D. E., Brown, J. S. \& Hammond, A. L. (2007) 'A review of the Open Educational Resources (OER) Movement: achievements, challenges, and new opportunities', February 2007. http://www.oerderves.org/wp-content/uploads/2007/03/a-review-of-theopen-educational-resources-oer-movement_final.pdf [Accessed 8 August 2011].

Bell, V. \& Rothery, A. (2006) 'E-Sharing: developing use of e-repositories and e-libraries for learning and teaching, in Is Information Technology Shaping the Future of Higher 
Education?', Proceedings of the 12th International Conference of European University Information Systems, Estonia. 28-30 June 2006.

Bissell, A. N. (2009) 'Permission granted: open licensing for educational resources', Open Learning, vol. 24, no. 1, pp. 97-106.

Borthwick, K. \& Dicken, A. (2010) 'Report 1: tracking the use of HumBox OER', [online]. Available at: http://www.llas.ac.uk/resourcedownloads/3233/humbox_tracking_report1.pdf [Accessed 8 August 2011].

Centre for Educational Research and Innovation and OECD Organisation for Economic CoOperation and Development (CERI). (2007) 'Giving knowledge for free', The Emergence of Open Educational Resources, [online]. Available at: http://www.oecd.org/document/41/ 0,3343,en_2649_35845581_38659497_1_1_1_1,00.html [Accessed 8 August 2011].

Creative Commons Organisation. (2011) http://creativecommons.org [Accessed 8 August 2011].

D'Antoni, S. (2008) 'Open educational resources the best way forward', Deliberations of an International Community of Interest, UNESCO Report, [online]. Available at: http:// learn.creativecommons.org/wp-content/uploads/2008/03/oer-way-forward-final-version.pdf [Accessed 8 August 2011].

Dholakia, U. M., King, W. J. \& Baraniuk, R. (2006) 'What makes an open education programme sustainable?', The case of connexions, [online]. Available at. http://www.oecd. org/dataoecd/3/6/36781781.pdf [Accessed 8 August 2011].

Downes, S. (2007) 'Models for sustainable open educational resources', Interdisciplinary Journal of Knowledge and Learning Objects, vol. 3, pp. 29-44.

Friesen, N. (2009) 'Open educational resources: new possibilities for change and sustainability', International Review of Research in Open and Distance Learning, vol 10, no. 5, pp. 1-14.

Goldberg, C. (2001) 'Auditing classes at M.I.T, on the web and free', New York Times, 4 April, [online]. Available at: http://web.mit.edu/ocwcom/MITOCW/Media/NYTimes_040301_ MITOCW.pdf [Accessed 8 August 2011].

Gunn, C. (2010) 'Sustainability factors for e-learning initiatives', Research in Learning Technology, vol 18, no. 2, pp. 89-103.

Joint Information Systems Committee (JISC). (2010) 'Open Educational Resource Programme', [online]. Available at: http://www.jisc.ac.uk/oer [Accessed 8 August 2011].

JISC Legal. (2011) 'Copyright Law Essentials (14/04/2011)', [online]. Available at: http:// www.jisclegal.ac.uk/LinkClick.aspx?fileticket $=$ J0cknzSYEG4\%3d\&tabid $=243$ [Accessed 8 August 2011].

Jorum. (2011) Learning to Share. http://www.jorum.ac.uk/ [Accessed 8 August 2011].

Kim, S., \& Ju, B. (2008) 'An analysis of faculty perceptions: attitudes towards knowledge sharing and collaboration in an academic institution', Library and Information Science Research, vol. 30, pp. 282-290.

Larsen, K. \& Vincent-Lancrin, S. (2005) 'The impact of ICT on tertiary education: advances and promises', Paper presented at the OECD/NSF/U Michigan Conference 'Advancing Knowledge and the Knowledge Economy", 10-11 January 2005, Washington, DC.

Multimedia Educational Resource for Learning and Online Teaching MERLOT. (2011) http:// www.merlot.org/merlot/index.htm [Accessed 8 August 2011].

Open Course Ware Consortium (OCWC). (2011) 'Courses'. http://www.ocwconsortium.org/ [Accessed 8 August 2011].

Rolfe, V. (2010a) 'Faculty sharing of scientific educational materials: drivers and barriers', Abstract. OER10, [online]. Available at: http://www.ucel.ac.uk/oer10/abstracts/1001.html [Accessed 8 August 2011].

Rolfe, V. (2010b) 'OER Staff Attitude Survey', Tag OERVAL, [online]. Available at: http:// www.jorum.ac.uk/ [Accessed 8 August 2011].

Rolfe, V., Alcocer, M., Bentley, E., Milne, D. \& Meyer-Sahling, J. (2008) Academic staff attitudes towards electronic learning in Arts and Sciences, European Journal of Distance Learning, [online]. Available at: http://www.eurodl.org/index.php?article=313 [Accessed 8 August 2011].

Rolfe, V., Fowler, M. \& Dyson, S. (forthcoming) 'Global OER awareness survey of science and healthcare professionals'. Diversity in Health and care. 
The William and Flora Hewlett Foundation. (2010) 'Open Educational Resources', Hewlett, [online]. Available at: http://www.hewlett.org/programs/education-program/open-educational-resources [Accessed 8 August 2011].

United Nations Educational, Scientific and Cultural Organization (UNESCO). (2002) Forum on the Impact of Open Courseware for Higher Education in Developing Countries. Final Report, [online]. Available at: http://unesdoc.unesco.org/images/0012/001285/128515e.pdf [Accessed 8 August 2011]. 